\title{
Involving patients with depression in research: survey of patients' attitudes to participation
}

\author{
Deborah Tallon, Jean Mulligan, Nicola Wiles, Laura Thomas, \\ Tim J Peters, Rodney Elgie, Debbie Sharp and Glyn Lewis
}

\author{
ABSTRACT \\ Background \\ Clinicians report barriers to involving their patients in \\ mental health research and have concerns that \\ participation may have negative effects. \\ Aim \\ To investigate patients' views on participating in a \\ primary care randomised controlled trial (RCT) \\ comparing two antidepressant drugs. \\ Design of study \\ Cross-sectional survey. \\ Setting \\ General practices, England. \\ Method \\ Six hundred and one trial participants were surveyed \\ about their reasons for, and experience of, participating. \\ Results \\ The questionnaire was completed by 252/601 (42\%) \\ participants. The most influential factors determining \\ participation were: wanting to help others with \\ depression $(94 \%, 95 \%$ confidence interval $[\mathrm{Cl}]=90$ to \\ $97 \%$ ) of responders rated this as 'important' or 'very \\ important'); friendly researchers $(94 \%, 95 \% \mathrm{Cl}=90$ to \\ $96 \%)$; and interest in the research $(88 \%, 95 \% \mathrm{Cl}=83$ \\ to $91 \%)$. Most were glad they took part and would \\ consider participating in future research. Ninety-six per \\ cent $(95 \% \mathrm{Cl}=92$ to $98 \%)$ reported that their \\ confidence in their GP had increased or remained \\ unchanged since referral. Qualitative analysis of free- \\ text responses indicated that patients found \\ participation beneficial and liked: being altruistic, doing \\ something positive, feeling supported by the \\ researchers, and having time to talk. Many gained \\ understanding of their depression and valued feedback \\ on their progress. A minority reported negative views, \\ which commonly related to taking antidepressants, and \\ answering questionnaires.

\section{Conclusion} \\ GPs have a vital role in facilitating patient involvement \\ in research but report barriers to referring depressed \\ patients to RCTs. However, this data suggests that \\ patients are willing to participate and many find this \\ beneficial. Understanding attitudes to participation in \\ mental health research is a crucial step in designing \\ trials that are more acceptable to patients and GPs. \\ This will strengthen the evidence for therapeutic \\ approaches in primary care. \\ Keywords \\ depression; general practice; patient participation; \\ qualitative research; randomised controlled trials.
}

\section{INTRODUCTION}

Depression is a common and debilitating condition that is usually treated in primary care. While guidelines on the management of depression exist, ${ }^{1}$ uncertainty remains due to the weakness of evidence supporting interventions in this area. ${ }^{2}$ Relevant randomised controlled trials (RCTs) in primary care would provide robust evidence that would inform and improve treatment options for patients. However, to be successful, they are dependent on collaboration with GPs and the timely recruitment and retention of sufficient participants.

Recruitment to RCTs is often difficult. Slow or inadequate recruitment has implications for trial costs, timeline, and validity, and may result in a trial being underpowered or even discontinued. ${ }^{3} \mathrm{~A}$ recent review of 122 multicentre trials in various clinical areas and settings (including mental health and primary care) found that less than one-third recruited to their original target within the original timeframe. ${ }^{4}$ Bower et al reviewed 39 published primary care trials (including seven mental health

D Tallon, BSc, MSc, research associate; J Mulligan, BSc, $P h D$, trial coordinator; $N$ Wiles, $B S c, P h D$, senior lecturer in epidemiology; L Thomas, BA, MPhil, research associate; TJ Peters, BSc, MSc, PhD, CStat, FFPH, professor of primary care health services research; $G$ Lewis, PhD, FRCPsych, professor of psychiatric epidemiology; D Sharp, PhD, FRCGP, professor of primary health care, Department of Community Based Medicine, University of Bristol, Bristol. R Elgie, immediate past president of GAMIAN-Europe.

\section{Address for correspondence}

Ms Deborah Tallon, School of Social \& Community Medicine, University of Bristol, Oakfield House, Oakfield Grove, Clifton, Bristol, BS8 2BN. E-mail: d.tallon@bris.ac.uk

Submitted: 26 May 2010; Editor's response: 29 June 2010; final acceptance: 13 August 2010.

() British Journal of General Practice

This is the full-length article (published online 28 Mar 2011) of an abridged version published in print. Cite this article as: Br J Gen Pract 2011; DOI: 10.3399/bjgp11X567036. 
trials) and found comparable recruitment difficulties. ${ }^{5}$ Only $29 \%$ of the trials recruited to timetable, $56 \%$ had to extend recruitment, and onethird required additional funds.

Other authors have described the particular difficulties of recruiting primary care patients into mental health trials. ${ }^{6-10}$ For example, one counselling trial was abandoned as only one patient was recruited by 25 GPs in a 5-month period. ${ }^{7}$ Similarly, a trial of computerised psychological therapy was discontinued after 1 year as GPs found trial recruitment difficult. ${ }^{6}$ These GPs indicated that the randomisation procedure compromised their role of providing patients with the best possible treatment, and that research took too much time and was inappropriate when patients were distressed. While GPs recognise the importance of mental health research, they also express concerns about its impact on the doctor-patient relationship. ${ }^{9}$

Consequently, depressed patients are not always given the opportunity to participate in research in the same way as they may be encouraged to participate in treatment decisions. ${ }^{9}$ However, clinicians can overestimate the negative impact of participating in psychiatric research, while underestimating potential benefits. ${ }^{11}$ For example, research questionnaires and interviews can be helpful in promoting self-realisation and facilitating therapy. ${ }^{11}$

Much of the research on patients' motivation for participating in research has focused on patients in secondary care and those with cancer. ${ }^{12,13}$ Little is known about the views of primary care patients with mental health problems.

The GenPod study, conducted by the authors, is a multicentre primary care RCT investigating genetic and clinical predictors of treatment response in depression. ${ }^{14}$ Despite good support from collaborating GPs, referrals to the study were fewer than anticipated; 256 (58\%) of collaborating GPs made no referrals, and a further $57(13 \%)$ referred only one. A nested qualitative study using semistructured interviews with GPs identified a number of barriers to recruiting patients with depression to a trial within consultations. ${ }^{9}$ GPs often viewed patients as vulnerable, in need of protection, and potentially unable to make clear decisions about participation. They also expressed concerns about the potentially negative impact of suggesting participation in research on the doctor-patient relationship.

This study aimed to elucidate patients' attitudes to participating in the trial, in order to inform the design of future research. The objectives were to investigate: patients' reasons for taking part; their experience of trial participation; views on future participation; and suggestions for making research more acceptable to patients.

\section{How this fits in}

Recruitment to RCTs is often difficult in primary care, and particularly in mental health research. GPs have a vital role in facilitating research, but express

concerns and difficulties in recruiting patients for trials. This study shows that patients with depression were willing to participate in research, found participation beneficial, and were particularly motivated by altruism, interest,

and supportive research staff. Understanding attitudes to participation in mental health research is a crucial step in designing and conducting successful, relevant, and inclusive trials that are acceptable to both patients and clinicians. Increasing the breadth of participation in terms of both practices and patients will increase the generalisability of findings.

\section{METHOD}

\section{Participants}

The GenPod protocol is published elsewhere. ${ }^{15}$ GPs from 104 practices in Bristol, Birmingham, and Newcastle referred patients aged between 18 and 74 years, presenting with a new episode of depression that they considered best treated with antidepressant medication. Six hundred and one eligible participants (with International Classification of Diseases [ICD]-10 depression assessed using the Clinical Interview Schedule-Revised [CIS-R], ${ }^{16}$ and a Beck Depression Inventory ${ }^{17}[\mathrm{BDI}$ score $>14$ ) were randomised to receive one of two antidepressants; $544(91 \%)$ completed follow-up at 6 weeks, and 485 $(81 \%)$ at 12 weeks.

\section{Trial feedback questionnaire}

Participants were sent a postal questionnaire after their 12-week follow-up. Questionnaires were sent out in four batches, thus some were received immediately after the final follow-up, and others several months later. Responders had the option of completing the questionnaire anonymously, and were encouraged to return a blank questionnaire if they did not want to participate. Up to two postal reminders were sent.

As there were no validated measures to assess motivation for research, or satisfaction with research participation, the questionnaire was informed by previous research in this area, discussion with the research team, and informal feedback provided by GenPod participants. The survey included closed questions with multiple-response options asking patients to rate the importance of seven factors in influencing their decision to participate (friendly researchers, altruism, flexible appointments, interest, GP request, better care, and free prescriptions), whether they would consider participating in research again, and whether their confidence in their GP had changed since taking part (Tables 2 and 3 ). Participants were also asked to provide free-text responses on what they liked most and least about 


\begin{tabular}{|c|c|c|c|}
\hline Characteristics & $\begin{array}{c}\text { Responders } \\
(n=252), n(\%)\end{array}$ & $\begin{array}{l}\text { Non-responders } \\
(n=349), n(\%)\end{array}$ & $P$-value \\
\hline \multicolumn{3}{|l|}{ Age group, years } & \multirow[t]{4}{*}{$<0.001$} \\
\hline $18-34$ & $69(27)$ & $176(50)$ & \\
\hline $35-54$ & $140(56)$ & $143(41)$ & \\
\hline $55-74$ & $43(17)$ & $30(9)$ & \\
\hline \multicolumn{3}{|l|}{ Sex } & \multirow[t]{3}{*}{0.001} \\
\hline Female & $192(76)$ & $216(62)$ & \\
\hline Male & $60(24)$ & $133(38)$ & \\
\hline \multicolumn{3}{|l|}{ Ethnicity } & \multirow[t]{3}{*}{0.046} \\
\hline White & $246(98)$ & $329(94)$ & \\
\hline Other $^{b}$ & $6(2)$ & $20(6)$ & \\
\hline \multicolumn{3}{|l|}{ Trial centre } & \multirow[t]{4}{*}{$0.039^{\circ}$} \\
\hline Bristol & $229(91)$ & $292(84)$ & \\
\hline Birmingham & $21(8)$ & $51(15)$ & \\
\hline Newcastle & $2(1)$ & $6(2)$ & \\
\hline \multicolumn{3}{|l|}{ Employment status } & \multirow[t]{7}{*}{0.009} \\
\hline Employed & $151(60)$ & $206(59)$ & \\
\hline Student & $10(4)$ & $13(4)$ & \\
\hline Retired & $16(6)$ & $5(1)$ & \\
\hline Houseperson & $31(12)$ & $46(13)$ & \\
\hline Unemployed job seeker & $10(4)$ & $31(9)$ & \\
\hline Unemployed due to ill-health & th 34 (13) & $48(14)$ & \\
\hline \multicolumn{4}{|l|}{ History of depression } \\
\hline Family history & $167(66)$ & $210(60)$ & 0.14 \\
\hline Previous depression & $183(73)$ & $252(72)$ & 0.96 \\
\hline Previous antidepressants & $143(57)$ & $182(52)$ & 0.28 \\
\hline \multicolumn{3}{|l|}{ Severity of depression ${ }^{d}$} & \multirow[t]{4}{*}{0.46} \\
\hline Mild & $24(10)$ & $27(8)$ & \\
\hline Moderate & $132(52)$ & $173(50)$ & \\
\hline Severe & $196(38)$ & $149(43)$ & \\
\hline \multicolumn{3}{|l|}{ Antidepressant treatment } & \multirow[t]{3}{*}{$<0.001$} \\
\hline Continued on medication & $173(69)$ & $165(47)$ & \\
\hline Discontinued medication & $79(31)$ & $184(53)$ & \\
\hline
\end{tabular}

aln addition to those presented here, a further five variables demonstrated no differences between responders and non-responders and are omitted for brevity, namely drug allocation, side-effects 2 weeks after randomisation, improvement in BDI (halving of baseline score) at 6 and 12 weeks, and remission at 6 weeks $(B D I<10)$. ${ }^{\circ}$ Other ethnicities:

Asian/British Asian $(n=3)$, Black/Black British $(n=3)$, mixed $(n=1)$, other $(n=1)$. 'Fisher's

exact test. ' $/ C D-10$ depression severity, assessed using the CIS-R. eSelf-reported adherence to study medication at last completed follow-up.

taking part, and their suggestions for making the research more acceptable to others.

\section{Other data}

Information on past medical history, illness severity, treatment allocation, number of completed followups, demographic factors, and treatment response was available from the trial database for all responders and non-responders to the feedback questionnaire.

\section{Analysis}

Sociodemographic and clinical characteristics of responders and non-responders were compared using $\chi^{2}$ tests to determine whether survey responders were representative of the GenPod participants. $\chi^{2}$ analyses also explored whether sociodemographic factors (indicated in the footnotes of Table 2) were associated with reasons for participating.

Free-text responses were analysed qualitatively by coding for themes and subthemes, and a framework for exploring the data was developed. ${ }^{18,19}$ Two authors independently reviewed all responses and developed tentative coding themes and subthemes. Consensus about the themes arising from the data was reached by discussion between the two researchers. One of the researchers then coded every response, and the other researcher independently coded a $50 \%$ sample of these. Codes for this $50 \%$ sample were compared, and discrepancies resolved through discussion. Quotations presented are broadly representative of the key themes and reflect a range of views.

\section{RESULTS}

Feedback was provided by 252 (42\%) of the 601 participants, and a further 25 returned blank questionnaires. None replied anonymously. Questionnaires were completed, on average, 8 months after the final follow-up (standard deviation [SD] 6 months, range 0-39 months).

Characteristics of responders $(n=252)$ and nonresponders $(n=349)$ are presented in Table 1. Younger people, males, those of non-white ethnicities, and those who had stopped taking their medication during the study were less likely to complete the questionnaire.

\section{Factors influencing the decision to participate} Helping others with depression in the future, friendly researchers, and being offered convenient appointments were most frequently rated as 'very important' factors influencing the decision to participate (Table 2). Interest in the research, and the GP's referral to the trial were also important motivators. Only one in six participants rated the possibility of better care as a very important reason for taking part.

Thirty-eight responders indicated they had 'another reason' for participating, with 37 providing a free-text response. Some of these linked to the options above but others cited needing or getting more help $(n=14)$; feeling ill $(n=2)$; negative views of medication $(n=2)$; or confidentiality/not feeling pressured $(n=1)$ as reasons for participating.

Exploratory analyses showed that the friendliness of research staff was more important to female participants than males, with $72 \%$ of females rating this as very important compared to just $54 \%$ of males $\left(\chi^{2}=7.50\right.$, degrees of freedom $\left.[\mathrm{df}]=2, P=0.024\right)$. Those with a history of depression treatment rated their interest in research and helping others as more 
Table 2. Reasons for participating in research.

\begin{tabular}{|c|c|c|c|c|}
\hline Reason & $\begin{array}{c}\text { Not important, } \\
n(\%)\end{array}$ & $\begin{array}{c}\text { Important, } \\
n(\%)\end{array}$ & $\begin{array}{c}\text { Very important, } \\
n(\%)\end{array}$ & $\begin{array}{c}\text { Responses, } \\
n^{\mathrm{a}}\end{array}$ \\
\hline Researchers were friendly ${ }^{b}$ & $16(6.4)$ & $65(26.0)$ & $169(67.6)$ & 250 \\
\hline To help others with depression in the future ${ }^{b, c}$ & $15(6.0)$ & $78(31.1)$ & $158(63.0)$ & 251 \\
\hline Appointments were convenient/flexible $e^{b, d}$ & $48(19.2)$ & $102(40.8)$ & $100(40.0)$ & 250 \\
\hline Was interested in the research ${ }^{\mathrm{b}, \mathrm{c}}$ & $31(12.5)$ & $147(59.3)$ & $70(28.2)$ & 248 \\
\hline My GP wanted me to take part ${ }^{\mathrm{b}}$ & $71(28.3)$ & $124(49.4)$ & $56(22.3)$ & 251 \\
\hline Thought I would get better medical care ${ }^{b}$ & $108(43.6)$ & $92(37.1)$ & $48(19.4)$ & 248 \\
\hline Free prescription ${ }^{b, d}$ & $206(83.4)$ & $29(11.7)$ & $12(4.9)$ & 247 \\
\hline
\end{tabular}

Some questionnaires were returned partially completed. ${ }^{\circ}$ Exploratory analyses considered age, sex, history of depression, depression severity, and previous treatment for depression. 'Exploratory analyses also considered family history of depression. ${ }^{\circ}$ Exploratory analyses also considered employment status.

important than those without: $32 \%$ versus $22 \%\left(\chi^{2}=\right.$ $7.73, \mathrm{df}=2, P=0.021)$, and $68 \%$ versus $56 \%\left(\chi^{2}=\right.$ 7.31, $\mathrm{df}=2, \quad P=0.026)$ respectively. Older participants (aged $55-75$ years) were more motivated by their interest in research $\left(\chi^{2}=10.42\right.$, df $=4, P=$ 0.034), and because the GP had asked them to participate; for example, $28 \%$ of those aged 55-75 years rated this as very important, compared to $21 \%$ aged $35-54$ years, and $22 \%$ aged $18-34$ years $\left(\chi^{2}=11.38, \mathrm{df}=4, P=0.023\right)$. As listed in the footnotes to Table 2, other factors were considered in these analyses, but no evidence of any differences was found.

\section{Views of trial participation}

Overwhelmingly, responses indicated a positive experience for patients (Table 3). Most $(87 \%, 95 \% \mathrm{Cl}$ $=82$ to $91 \%$ ) were glad they took part. No statistical evidence could be found to suggest that this percentage varied by sex, age, or employment status (demographic characteristics associated with nonresponse to the survey). Patients who had continued to take their medication during the trial were more likely to report being glad they took part than did those who discontinued ( $91 \%$ versus $79 \%$, Fisher's exact $P=0.02$, df $=2$ ).

Overall, $74 \%(95 \% \mathrm{Cl}=68$ to $80 \%)$ would consider future participation in research. Only one responder indicated that he regretted taking part and that this was because 'I took part in the hope [the antidepressants] would work!'. Only $5 \%(95 \% \mathrm{Cl}=3$ to $8 \%$ ) would not consider participating in future research and, reassuringly, none of these patients had lost confidence in their GP (Table 3). Indeed, 96\% $(95 \% \mathrm{Cl}=92$ to $98 \%)$ of patients reported that confidence in their GP had increased or remained unchanged since their referral to GenPod.

\section{Positive views of participation}

Patients stated what they liked most about participation. A number of themes relating to positive experiences emerged from thematic analysis of these free-text responses $(n=206)$ (Box 1). For each theme, illustrative quotations are provided.

\section{Helping research and others with depression} Altruism was the most commonly cited positive response. Responders liked being able to help, and hoped research would help improve the treatment of depression:

'The hope that my experience and that of others taking part could help other people in a similar situation.' (participant 10)

II felt that I was being helped yet helping others at the same time. I cannot stress how important I felt the research and team were.' (participant 104)

'The feeling it gave me to be giving back to the health service and medical services.' (participant 161)

'Being part of new developments and aiming toward improving treatment for myself and others.' (participant 96)

\section{Doing something positive}

Many found participation rewarding and hoped that something positive would come from their illness. Some said that the best aspect of participating was that it had helped them, while others found research interesting. The study gave some a sense of hope that their depression would improve:

'It gave me the opportunity to focus at a time when I felt desolate and unable to contribute to home or work.' (participant 21)

'While feeling totally useless and depressed, it 


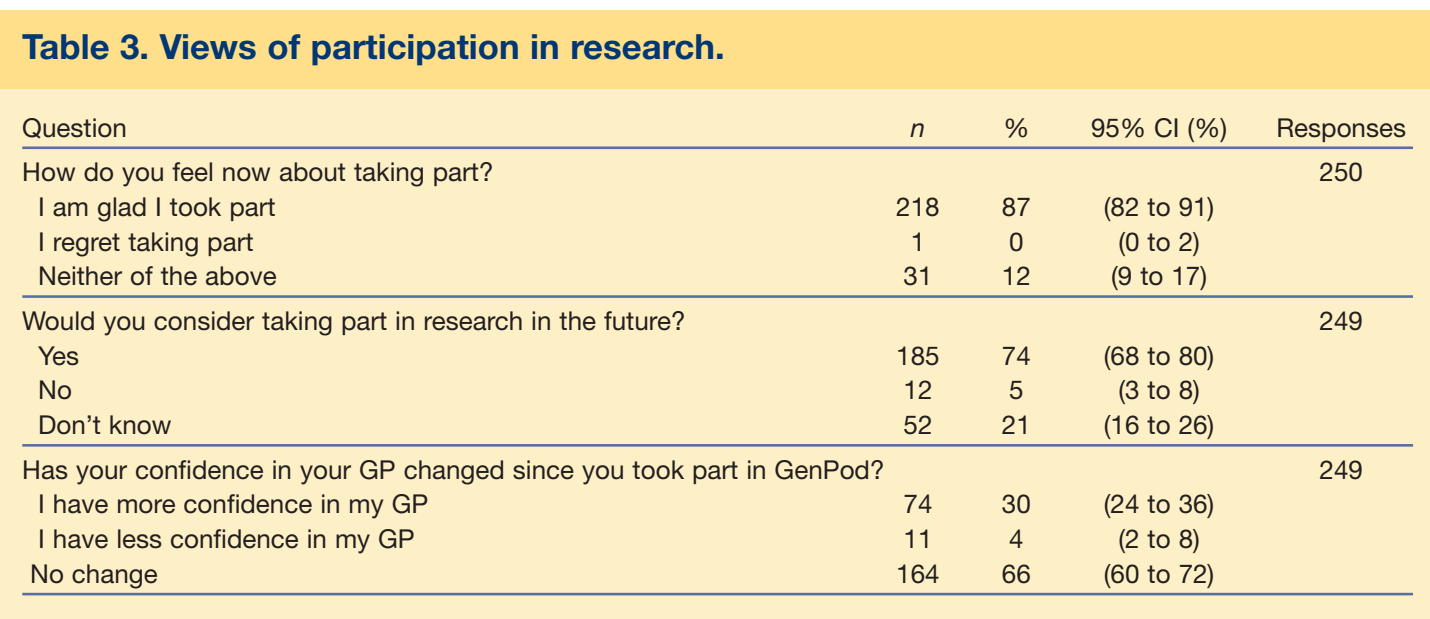

felt like something positive could come out of my illness.' (participant 187)

\section{Feeling supported}

Many participants felt supported by the research team. Having the opportunity and extra time to talk to the researcher was particularly valued. Being seen on a one-to-one basis, and having appointments at home made the experience more relaxed. Patients described the researchers as friendly, patient, caring, understanding, and helpful. The researcher was also a source of information about depression and antidepressant medication. Participation also helped patients to feel less isolated:

'The researcher was very friendly and had time to listen to everything I was saying and was very helpful.' (participant 92)

'It was informal and relaxed. I felt as though there was genuine interest in my condition.' (participant 108)

'It was nice that someone was interested in my problem, and I appreciated the one-to-one meeting with friendly and understanding researchers. It made me feel less alone.' (participant 146)

\section{Self-awareness and feedback on depression}

Taking part in the study gave patients an opportunity to reflect on their mental health and to gain a better understanding of their depression. For many, this was viewed as the most positive aspect of participation. The trial follow-up assessments (by telephone at 2 weeks, and face-to-face at 6 and 12 weeks) were particularly valued, as these gave participants an idea of how their responses to questionnaires had changed over time; thus many received positive feedback on their progress:
'Seeing the difference in my answers to the questions in the questionnaires from the start to the finish. Also the questionnaires made me face and think about how I was feeling.' (participant 239)

'It helped me with coming to terms with my depression.' (participant 44)

'I liked the regular follow-ups and the opportunity to talk through how I was feeling during the 12 weeks. It helped me to understand why I felt low and to actually see an improvement in my mood.' (participant 181)

Finally, there were several positive remarks about the antidepressants. These included: not having to pay a prescription charge; 'positive' side-effects such as weight loss; that the dose could be adjusted by the GP; and that the researcher provided monitoring, information, and reassurance about side-effects.

\section{Negative views of participation}

Patients were asked to state what they liked least about participation, and only 140 responders (56\%) answered this question. The most common response was 'nothing' $(n=45)$. The most negative themes emerging from the remaining 95 responses related to the antidepressant medication (having to take it and having side-effects) $(n=35)$ and completing the questionnaires $(n=27)$ :

'I didn’t like being on medication.' (participant 12)

'The side-effects at the beginning of taking the medication; dry mouth, hot sweats, etc.' (participant 244)

Some considered the questionnaires to be lengthy, repetitive, and difficult to understand or answer, 
particularly when they felt most depressed and had difficulty concentrating:

'Having to answer multiple-choice questions [a crude tool] of a very personal nature.' (participant 79)

'Some of the questions were a bit difficult to answer, didn't always understand them.' (participant 163)

Others $(n=10)$ found the appointments inconvenient or time consuming. A few patients disliked thinking about, admitting, or discussing their depression; some found this difficult or upsetting. Finally, six patients reported the blood test to be their least favoured aspect of the study:

'Sometimes the visits were difficult to fit in with my work.' (participant 115)

'I don't really like people to know that I suffer from depression.' (participant 8)

'Having to discuss how I felt. I prefer to just 'get on with it' rather than "wallow".' (participant 155)

'Having to think about my problems and how l'm feeling.' (participant 237)

\section{Suggestions for improving research for future participants}

Only $47(19 \%)$ responders suggested ways to improve the trial experience. Most comments concerned: making the questionnaires shorter, easier, or more accessible (for example, available online); offering more follow-ups, support, or counselling; and for past volunteers, GPs, or the researchers to reassure future participants about the acceptability of the trial. Other suggestions included offering refreshments, reminders for appointments, and personal feedback, and for the researcher to be sensitive and helpful.

\section{DISCUSSION}

\section{Summary of main findings}

GPs hold the doctor-patient relationship in high regard and seek to protect their patients from what they consider to be an unnecessary burden. ${ }^{9}$ However, this study has shown that many people welcome the opportunity to contribute to research that may improve the understanding and treatment of a condition they know to be debilitating. Many found the study an opportunity to do something positive during a very difficult time, while benefiting from enhanced support and feedback. However, some did express difficulty with the questionnaires and negative views of antidepressants.

\section{Strengths and limitations of the study}

Two hundred and fifty-two participants provided feedback on their motivations for, and experience of, participating in a RCT, making this one of the largest surveys of its kind. The use of both fixed-choice and free-text responses allowed both quantitative and qualitative analysis of the patients' views and experiences. Furthermore, as the views of collaborating GPs had already been elicited, ${ }^{9}$ it was possible to directly compare these to the patients' experiences.

Nonetheless, there are limitations and these mainly relate to the possibility of selection bias and the generalisability of the findings. For example, GPs did report that some of their patients declined to be referred to the trial and these figures were not routinely collected. It is also possible that a GP's attitude to research influenced their patients' decision to take part in the trial.

Patients' views on participation presented here reflect the views of those who had agreed to be referred to the trial and to be randomised, and their views may have differed from those who declined referral, or decided not to participate after their referral (either prior to ascertainment of eligibility $[n=90]$ or prior to randomisation $[n=2])$. Ascertaining the views of patients who decline participation is challenging, but useful to inform the design of more acceptable research trials. Researchers and recruiting GPs should record patients' reasons for declining if these are given. The number of patients who decline, and their anonymised sociodemographic data should also be collected, in order to establish whether consenting trial participants are representative. The use of electronic medical records to identify potential participants may facilitate this, as non-identifiable information on age, sex, and ethnicity are routinely collected.

The survey response rate was $42 \%$, and a further 24 (4\%) patients returned blank questionnaires and non-response may bias the findings. However, there were few differences between those who did or did not complete the questionnaire in terms of the history or severity of depression, treatment response, or side-effects. Younger individuals and men were less likely to provide feedback. The potential for bias is difficult to assess, although with one exception, no evidence was found to suggest that demographic characteristics associated with non-response (for example, age, sex, and ethnicity) were associated with particular views of participation. The observation that those who discontinued their medication were 
less likely to respond and (among the responders) less likely to report being glad they took part means that there is some potential for bias in respect of this factor. Overall, though, the authors think it unlikely that the low response rate seriously biased the study finding that the participants in GenPod had a positive experience of participation.

\section{Comparison with existing literature}

Embedding qualitative research on participants' views within a trial has been shown to be particularly useful in improving recruitment rates. ${ }^{20}$ Although GenPod did not employ in-depth qualitative interviews, the use of free-text responses in the survey allowed participants to voice more detailed and varied views. For example, patients provided pertinent and informative suggestions for making the trial methodology more acceptable for future volunteers. Involving service users in research is now actively encouraged, and all the responders in this survey can be viewed as consumer consultants on the research process. Service users can also provide a valuable contribution to other aspects of research, such as research priority setting, planning, research conduct, interpretation of results, and dissemination. ${ }^{21}$ A number of organisations offer information and guidelines on facilitating such involvement. ${ }^{22-24}$

As others have reported, ${ }^{11}$ this study found that clinician and patient views differed, with the practitioner overestimating the negative aspects of participation and underestimating positive aspects. GPs were concerned about burdening their patients and the adverse effects of trial recruitment on the doctor-patient relationship. ${ }^{9}$ In contrast, only one of the 252 GenPod responders regretted taking part, and very few lost confidence in their GP following participation.

Participants benefited from the enhanced support and feedback they received as part of the trial, and the friendliness of research staff was very important to them. These factors have also emerged in other research, ${ }^{11,25,26}$ and suggest that respect, support, and feedback from researchers are important for recruitment and retention. As such, they should be considered when developing recruitment strategies, particularly for vulnerable groups.

GPs highlighted difficulty in introducing the study during a difficult and lengthy consultation ${ }^{9}$ with a newly diagnosed patient with depression, suggesting that not all potential participants are given the opportunity to participate in trials. This may affect recruitment rates, with implications for study design and the costs, and may also limit the generalisability of research findings. Perhaps GPs should assume that patients would want to participate unless they have stated otherwise.
Evidence suggests such an 'opt-out' approach may increase response rates, make a study sample more representative, and be a better recruitment strategy for studies with low risk to participants. ${ }^{27,28}$

\section{Implications for future research and clinical practice}

GPs have an important 'gate-keeping' role in recruitment to all RCTs in primary care, with researchers often being reliant upon GPs to actively encourage patient participation in research. GP collaboration was crucial to the GenPod trial's success, with most participants citing the GP's introduction of the study as an important motivator.

Despite GPs' concerns about referring patients with depression to RCTs, ${ }^{6,9}$ these data suggest some patients with depression are willing to participate and find this rewarding. These results should encourage GPs to inform all patients of the opportunities for taking part in research and offer the choice about whether or not to participate. This would mirror the collaborative approach to treatment decisions. Understanding both GP and patient attitudes to participating in mental health research is crucial to finding effective strategies for improving recruitment to such trials. This in turn will lead to more successful, generalisable, and useful research that can inform treatment decisions in primary care.

The development of the Primary Care Research Network $^{29}$ and local schemes such as the Primary Care Incentive Scheme in the South West are both aimed at increasing primary care practitioners' knowledge and interest in participating in research of direct relevance to caring for patients in the primary care setting. Making sure GPs see the publications resulting from their involvement is another way of ensuring that they have the necessary information regarding the advantages and disadvantages for their practice and patients of being partners in the research process.

\section{Funding body}

This work was funded by the Medical Research Council (grant G0200243). The funder had no role in the study design; collection, analysis, and interpretation of data; the writing of the report; or the decision to submit for publication.

\section{Ethical approval}

South West Multicentre Research Ethics Committee.

\section{Competing interests}

The authors have stated that there are none.

\section{Acknowledgements}

We are grateful to the GenPod participants and our collaborating GPs. We thank Caroline Baker for administrative support. We also thank the GenPod Trial Steering Committee and Data Monitoring Committee for guidance, and the Mental Health Research Network for supporting the study.

\section{Discuss this article}

Contribute and read comments about this article on the Discussion Forum: http://www.rcgp.org.uk/bjgp-discuss 


\section{REFERENCES}

1. National Institute for Health and Clinical Excellence (NICE) Depression: management of depression in primary and secondary care. London: NICE, 2004.

2. Middleton H, Shaw I, Hull S, Feder G. NICE guidelines for the management of depression. BMJ 2005; 330(7486): 267-268.

3. Hunt CJ, Shepherd LM, Andrews G. Do doctors know best? Comments on a failed trial. Med J Aust 2001; 174(3): 144-146.

4. Campbell MK, Snowdon C, Francis D, et al. Recruitment to randomised trials: strategies for trial enrolment and participation study. The STEPS study. Health Technol Assess 2007; 11(48): iii, ix -105 .

5. Bower P, Wilson $\mathrm{S}$, Mathers N. How often do UK primary care trials face recruitment delays? Fam Pract 2007; 24(5): 601-603.

6. Hetherton J, Matheson A, Robson M. Recruitment by GPs during consultations in a primary care randomized controlled trial comparing computerized psychological therapy with clinical psychology and GP care: problems and possible solutions. Prim Health Care Res Dev 2004; 5: 5-10.

7. Fairhurst K, Dowrick C. Problems with recruitment in a randomized controlled trial of counselling in general practice: causes and implications. J Health Serv Res Policy 1996; 1(2): 77-80.

8. Katz T, Fisher P, Katz A, Feder G. The feasibility of a randomised, placebo-controlled clinical trial of homeopathic treatment of depression in general practice. Homeopathy 2005; 94(3): 145-152.

9. Mason VL, Shaw A, Wiles NJ, et al. GPs' experiences of primary care mental health research: a qualitative study of the barriers to recruitment. Fam Pract 2007; 24(5): 518-525.

10. King M, Broster G, Lloyd M, Horder J. Controlled trials in the evaluation of counselling in general practice. Br J Gen Pract 1994; 44(382): 229-232.

11. Marshall RD, Spitzer RL, Vaughn SC, et al. Assessing the subjective experience of being a participant in psychiatric research. Am J Psychiatry 2001; 158(2): 319-321.

12. Ross S, Grant A, Counsell C, et al. Barriers to participation in randomised controlled trials: a systematic review. J Clin Epidemiol 1999; 52(12): 1143-1156.

13. Fayter D, McDaid C, Ritchie G, et al. Systematic review of barriers, modifiers and benefits involved in participation in cancer clinical trials. York, UK: Centre for Reviews and Dissemination, University of York, 2006.

14. Lewis G, Mulligan J, Wiles N, et al. Polymorphism of the 5-HT transporter and response to antidepressants: randomised controlled trial. Br J Psychiatry 2011 Jan 24. [Epub ahead of print].
15. Thomas L, Mulligan J, Mason V, et al. GENetic and clinical Predictors Of treatment response in Depression: the GenPod randomised trial protocol. Trials 2008; 9: 29 .

16. Lewis G, Pelosi AJ, Araya R, Dunn G. Measuring psychiatric disorder in the community: a standardized assessment for use by lay interviewers. Psychol Med 1992; 22(2): 465-486.

17. Beck AT, Ward CH, Mendelsohn M, et al. An inventory for measuring depression. Arch Gen Psychiatry 1961; 4: 561-571.

18. Crabtree BF, Miller WL. Using codes and code manuals: a template organizing style of interpretation. In: Crabtree BF, Miller EL (eds). Doing qualitative research. Thousand Oaks, CA: Sage Publications, 1999; 163-178.

19. Miles MB, Huberman AM. Qualitative data analysis. Thousand Oaks, CA: Sage Publications, 1994.

20. Donovan JL, Mills N, Smith M, et al. Improving design and conduct of randomised trials by embedding them in qualitative research: ProtecT (prostate testing for cancer and treatment) study. BMJ 2002; 325(7367): 766-770.

21. Oliver S, Clarke-Jones L, Rees R, et al. Involving consumers in research and development agenda setting for the NHS: developing an evidence-based approach. Health Technol Assess 2004; 8(15): 1-148.

22. INVOLVE: promoting public involvement in NHS, public health and social care research. http://www.invo.org.uk/index.asp (accessed 16 Sep 2010).

23. James Lind Alliance. Establishing working partnerships. http://www.lindalliance.org/Patient_Clinician_Partnerships.asp (accessed 16 Sep 2010).

24. Faulkner A. Guidance for good practice: service user involvement in the UK. mental health research network. London: Service User Research Group England, 2005.

25. Murphy MR, Escamilla MI, Blackwell PH, et al. Assessment of caregivers' willingness to participate in an intervention research study. Res Nurs Health 2007; 30(3): 347-355.

26. Rosen C, Grossman LS, Sharma RP, et al. Subjective evaluations of research participation by persons with mental illness. J Nerv Ment Dis 2007; 195(5): 430-435.

27. Junghans $C$, Feder G, Hemingway H, et al. Recruiting patients to medical research: double blind randomised trial of 'opt-in' versus 'opt-out' strategies. BMJ 2005; 331(7522): 940.

28. Hewison J, Haines A. Overcoming barriers to recruitment in health research. BMJ 2006; 333(7562): 300-302.

29. National Institute for Health Research Primary Care Research Network. http://www.crncc.nihr.ac.uk/about_us/pcrn (accessed 22 Feb 2011). 